\title{
Intrusions in preschoolers' recall of traumatic childhood events
}

\author{
MARK L. HOWE, MARY L. COURAGE, and CAROLE PETERSON \\ Memorial University, St. John's, Newfoundland, Canada
}

\begin{abstract}
We investigated the presence of intrusions in preschoolers' memories for traumatic incidents by examining 30-, 36-, and 48-month-olds' initial and 6-month recall of traumatic events that required emergency room treatment. The basic findings were (1) the number of preschoolers who produced an intrusion at the 6th month's interview declined with age, (2) only the youngest preschoolers produced reliably more intrusions at 6 months than initially, (3) the amount of intruded information did not vary with age, and (4) the amount of information correctly recalled about the target traumatic event increased with age and was not affected by the presence of intrusions at any age. That preschoolers were able to recall considerable information concerning the target event, regardless of whether they did or did not produce intrusions, has implications for the veracity of their memories of trauma in real-life situations over extended retention intervals.
\end{abstract}

How common are intrusions in children's memories for traumatic incidents? This question has taken on considerable importance in recent years, particularly as the veracity of memory for early childhood trauma has become inordinately prominent in the legal, psychotherapeutic, and memory-research communities. Indeed, the question of whether adults and children can remember traumatic events from their childhoods has been fraught with controversy, particularly because the veracity of memory per se is a contentious issue. For example, it is well known that adults, as well as children (particularly preschoolers), are suggestible and can often be misled about details of witnessed events (Ceci \& Bruck, 1993). Although the aspects of these events that people can be misled about are typically peripheral in nature, recent studies have shown that entire events can be implanted and adopted as "real" memories by children (e.g., Ceci, Leichtman, \& White, in press) as well as adults (e.g., Loftus \& Coan, in press).

Although "implantation" and misinformation studies have provided us with further evidence attesting to memory's well-known constructive (Paris \& Lindauer, 1977) and reconstructive (Hasher \& Griffin, 1978) nature, very little is known about the role intrusions play in "tainting" memory. This is especially important when it comes to assessing the reliability of preschoolers' memories, because they are often the sole witnesses to traumatic events. Put simply, because preschoolers are susceptible to external suggestions and to standard retroactive interference effects (Howe, in press), it may be the case that

Preparation of this article was supported by Grants OGP0003334 (to M.L.H.), OGP0093057 (to M.L.C.), and OGP0000513 (to C.P.) from the Natural Sciences and Engineering Research Council of Canada. Correspondence should be addressed to M. L. Howe, Department of Psychology, Memorial University of Newfoundland, St. John's, Newfoundland, Canada A1B 3X9 (e-mail: mhowe@kean.ucs.mun.ca). they are also susceptible to what has recently been called autosuggestion (see Brainerd \& Reyna, in press). That is, internally generated information may also be more likely to interfere with, or intrude into, younger children's recall of a target traumatic event, particularly if those intrusive events are similar to the target event.

The literature on intrusions in children's recall is relatively sparse. What does exist suggests that in the presence of misinformation, children infrequently produce intrusions in addition to the misinformation (e.g., Howe, 1991; Marche \& Howe, in press). However, it is not clear whether intrusions are likely in the recall of children who have not been misled. This is critical because, as Poole and Lindsay (in press) point out, there exists a widespread belief that preschoolers' recall, albeit less detailed than older children's and adults', is highly accurate in the absence of misinformation. These authors also point out that such notions are based on studies in which recall has been elicited following a fairly short retention interval (usually a few days). What this means is that relatively few events have intervened between the time of the target event and the time of recall of that event. When longer retention intervals have been used, inaccuracy rates have tended to climb dramatically (e.g., Flin, Boon, Knox, \& Bull, 1992; Poole \& White, 1993).

In the present investigation, we were concerned about whether long-term retention of documented traumatic incidents was subject to intrusions in memory. Specifically, we were interested in the degree to which such memories were pliable over a 6-month retention interval, becoming "blended" or "rewritten" during that interval through intrusions of other events. In addition, we were interested in the possibility that the interrogation situation itself might reinstate (e.g., see Howe, Courage, \& Bryant-Brown, 1993), and therefore lead to the unsolicited reporting of, other traumatic experiences that may intrude into the recall of the target traumatic event. By in- 
trusion we mean that the child interjects into his or her narrative recall of a target event part or all of another event similar to the target event. Often, such intrusions would be scored as errors of commission. In order to distinguish intrusions from errors of commission, the elements being recalled had to meet two criteria. First, the elements had to form part of another, nontarget episode. For example, consider a child who incorrectly recalled that he or she had received a lollipop rather than a popsicle following emergency room treatment. If this was an isolated error, then it would normally be scored as an error of commission. However, if this error was embedded in a larger context of other incorrect (i.e., nontargetted event) material (e.g., "I got a lollipop when I hurt my arm and went to the hospital," when in fact the targetted event was about an eye injury), then it would normally be scored as an intrusion. To determine whether the error in this latter case was in fact an intrusion, we applied our second criteria - namely, confirmation by a parent that this nontargetted event had indeed occurred. Thus, our estimates of the number of intrusions may be somewhat conservative, because isolated and unconfirmed details about nontargetted events may in fact have been intrusions.

Finally, we were concerned with any developmental differences that might occur during the preschool years. Because the preschool period is a time of rapid cognitive change, it would not be unreasonable to expect differences in recall of traumatic events during this period (see Howe, Courage, \& Peterson, 1994). Similar age differences might be expected for the effects of other (intervening) experiences on the long-term retention of a target traumatic event.

\section{METHOD}

We investigated intrusions in recall of traumatic events by analyzing preschoolers' recall protocols for events that required outpatient emergency room treatment for fractures requiring casting, lacerations requiring suturing, and other anomalous injuries (e.g., dog bites). For the purposes of this article, we selected 32 children in three of the age ranges we reported previously (Howe et al., 1994), from whom data were available from both immediate and 6th month's interviews (15 children included were also reported in the previous article and 17 have been interviewed since). Of the 32 children, 12 ( 5 males, $7 \mathrm{fe}$ males) had an average age of 30 months (SD 53 months), 8 ( 2 males, 6 females) had an average age of 36 months (SD 52.6 months), and 12 ( 7 males, 5 females) had an average age of 48 months (SD 53.4 months). All of the children were White and came from predominantly lower middle class homes.

Parents were approached in the emergency room by a researcher who asked for permission to visit them at their home within a few (usually 3-5) days. At that time, the researcher first interviewed the child and then the parents about the events surrounding the incident. Interviews consisted of a free-recall session followed by a standardized cued-recall segment. Free recall was used to evaluate the child's spontaneous recollection of the incident and the treatment. Children were simply asked to "tell me what happened when you got hurt." No time limit was imposed on free recall, and children were encouraged to continue their narrative using nondirective prompts (e.g., "Really?" "Tell me more about it." "Was there anything else?" "And then what happened?"). The cued-recall segment reported here consisted of open-ended questions (e.g., "Who was with you when you got hurt?" "Who took you to the hospital?" "What did you do while you were waiting to see the doctor?") that were used to elicit additional information. Again, no time limit was imposed on answering these questions. In those instances in which parents were present during their child's interview, they were asked not to prompt or interrupt the child's narrative recall. Parental interviews followed the same format, and, in addition, the parents rated (on a 6-point scale) their child's level of stress at the time of the traumatic incident and during the emergency room procedure. Although this scale has not been standardized on a large sample, it is consistent with those administered by other researchers in this area (e.g., Goodman, Bottoms, Schwartz-Kenney, \& Rudy, 1991). Finally, parents were asked not to rehearse the incident with the child over the ensuing 6-month retention interval. Following 6 months, the children were interviewed again using free recall followed by cued recall. The cued-recall segment this time was based on the transcript of their earlier interview and that of their parents. All of the interviews were tape recorded and subsequently transcribed for memory analyses. Two raters scored $30 \%$ of the narratives, with an acceptable interrater reliability of $90 \%$. Any disagreements were resolved through discussion. The remaining protocols were scored by a single rater.

\section{RESULTS}

For the purposes of the present analyses, the narratives were coded according to the number of correct details recalled about the target event and the number of details concerning any intruded event. Accuracy of the details concerning the target event was determined by examining the correspondence between the parents' and children's reports of the events and from hospital records. Accuracy of the details from an intruded event was determined solely on the basis of parental confirmation. An intrusion was identified when the child's narrative contained details of another traumatic event that occurred either prior to the target event or in the interval between the initial and the 6th month's interview. These intrusions were sometimes coherent units containing several details of another event. For example, A.L., 28 months old at the time of an eye injury, was relating the details of that injury at the 6th month's interview when he spontaneously added (during cued recall) that the "doctor had fixed my tooth" and had "put medicine in my mouth." His mother confirmed that he had an injury to his mouth in the preceding month, one that required dental work in the emergency room.

Other intrusions were less coherent and more fragmentary. For example, N.P., 41 months old when she fell and fractured her arm, was relating the details of that injury at the 6th month's interview when, in response to a prompt for more information about what happened after the fall, she replied that she "went to the doctor with my jammies (pyjamas) on." In fact, the accident in question had happened outside during the day. However, according to her mother, N.P. had recently been taken to the emergency room for another incident and had been wearing pyjamas at that time.

Like correct recall of the target event, intrusions were scored in terms of the number of details they contained. As already mentioned, only those details that were confirmed by the parents were scored as intrusions, with unconfirmed details and fantasy items (e.g., "I was dead") being ignored. Again, what this means is that 
our estimate of intrusion rates is actually a conservative one.

There were three sets of findings of interest: (1) the number of children at each age who produced intrusions at 6 months and, for comparative purposes, at the initial interview, (2) the amount of information contained in recall of the target event and in recall of the intruded event(s) for each age at the 6-month interview, and (3) the relationship, if any, between stress levels and intrusions. Concerning Finding 1 above, Figure 1 shows the percentage of children at each age who produced at least one intrusion at the initial and the 6th month's interviews. It is clear from this figure that, across interviews, intrusions were more prevalent at 6 months than initially, but only for the younger preschoolers (30- and 36-month-olds). Cochran's $Q$ test (on the raw frequencies) indicated that although there were no differences between the initial and 6 th month's interviews in the number of children who produced intrusions for 36- or 48-month-olds, significantly more children produced intrusions at 6 months than at the initial interview for the 30 -month-olds $\left[\chi^{2}(1, N=12\right.$ pairs $\left.)=5.00, p<.05\right]$. Chi-square analyses of age differences in the number of children who produced intrusions at the initial interview were not reliable $\left[\chi^{2}(2, N=32)=0.98\right]$; however, these differences were reliable for the 6 th month's interview $\left[\chi^{2}(2, N=32)=\right.$ $8.21, p<.02$ ]. Follow-up tests of this latter result confirmed that the locus of this age difference was confined to the 30 - versus 48 -month-old comparison [ $\chi^{2}(1, N=$ 24) $=8.22, p<.01]$.

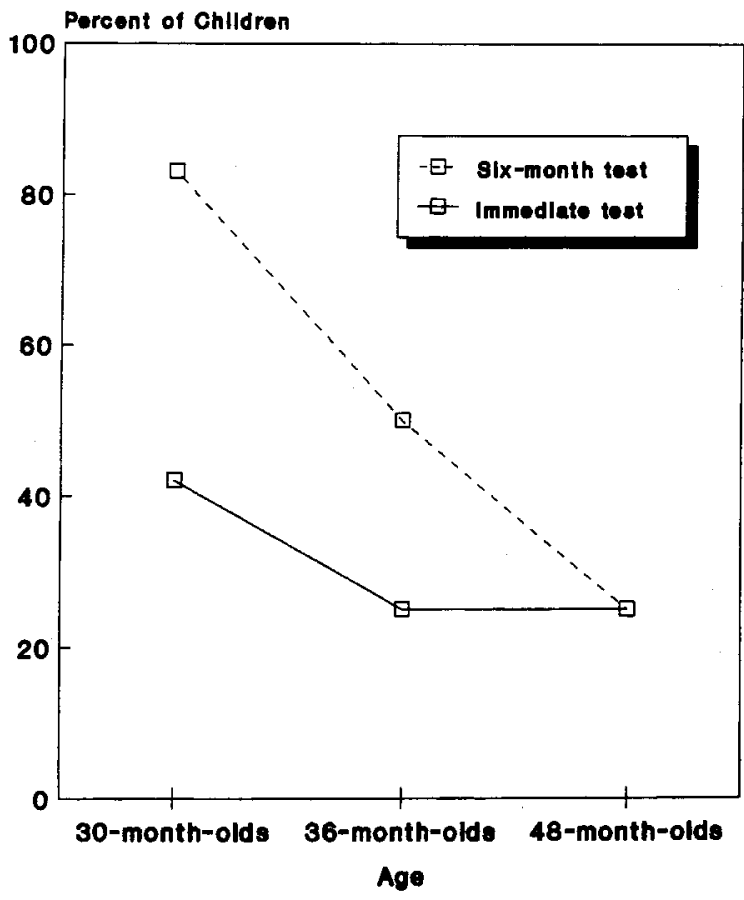

Figure 1. Percentage of preschoolers who exhibited at least one intrusion in their recall of a traumatic event at their immediate interview (3-5 days later; solid line) and their interview 6 months later (dashed line).
Concerning Finding 2 above, the amount of information correctly recalled about the target event and the amount of intruded information is shown as a function of age in Figure 2. These data were analyzed using a series of planned-comparison $t$ tests. First, as can be seen in Figure 2 (and was confirmed statistically), age differences in the amount of correct target information recalled were reliable. Using one-tailed tests, these differences were significant for each of the age comparisons [30month-olds $(M=7.50, S D=5.58)$ vs. 36-month-olds $(M=13.13, S D=3.26), t(18)=2.84, p<.01 ; 36$ - vs. 48 -month-olds $(M=19.58, S D=6.05), t(18)=3.09$, $p<.005 ; 30$ - vs. 48-month-olds, $t(22)=5.10, p<.001]$. Additional tests confirmed that there were no age differences in the amount of information intruded [30-montholds $(M=3.40, S D=1.50)$ vs. 36-month-olds $(M=$ $3.50, S D=0.87), 36$ - vs. 48 -month-olds $(M=3.33, S D=$ $0.47)$, and 30- vs. 48-month-olds, all $t \mathrm{~s}(5-12)<1]$. Thus, whereas there are clear developmental improvements in the amount of target information recalled, there are no age differences in the amount of intruded information. That the amount of information intruded in recall remains age invariant also stands in contrast to the finding that the percentage of children producing an intrusion declines with age.

Second, when tests were conducted to determine whether children who produced intrusions recalled less of the correct target information (30-month-olds, $M=$ $6.80, S D=5.79 ; 36$-month-olds, $M=13.25, S D=3.11$; 48-month-olds, $M=22.67, S D=4.64)$ than did children who did not produce intrusions (30-month-olds, $M=$ $11.00, S D=2.00 ; 36$-month-olds, $M=13.00, S D=3.26$; 48-month-olds, $M=18.56, S D=6.11$ ), the results indicated that there were no differences for any of the age groups [all $t \mathrm{~s}(6-10)=0.11-1.8$, not significant using two-tailed tests]. Thus, intrusions apparently did not interfere with correct target recall. Tests also indicated that subjects who produced intrusions recalled more material about the target event than about the intruded event. This difference was significant for the two older age groups [matched $t(3)=5.05, p<.01$, for 36-montholds; matched $t(2)=5.48, p<.025$, for 48 -month-olds] and approached significance for the youngest age group [matched $t(3)=5.05, p<.07$, for 30-month-olds].

Finally, concerning Finding 3 above, average stress scores were obtained for those children producing intrusions $(M=4.05, S D=0.93, n=17)$ and those who did not $(M=4.54, S D=0.80, n=15)$ at the 6th month's interview. A $t$ test confirmed that this difference was not reliable $[t(30)=1.63]$. Thus, rated stress levels were not related to whether subjects produced intrusions.

\section{DISCUSSION}

There are three sets of basic findings from this study - namely, those concerning intrusion frequency, those concerning amount of information intruded, and those concerning stress and intrusions. To begin, consider the intrusion frequency findings. There are two important results. First, across interviews, the number of children who produced intrusions was greater at the 6 month's interview than at the initial in- 


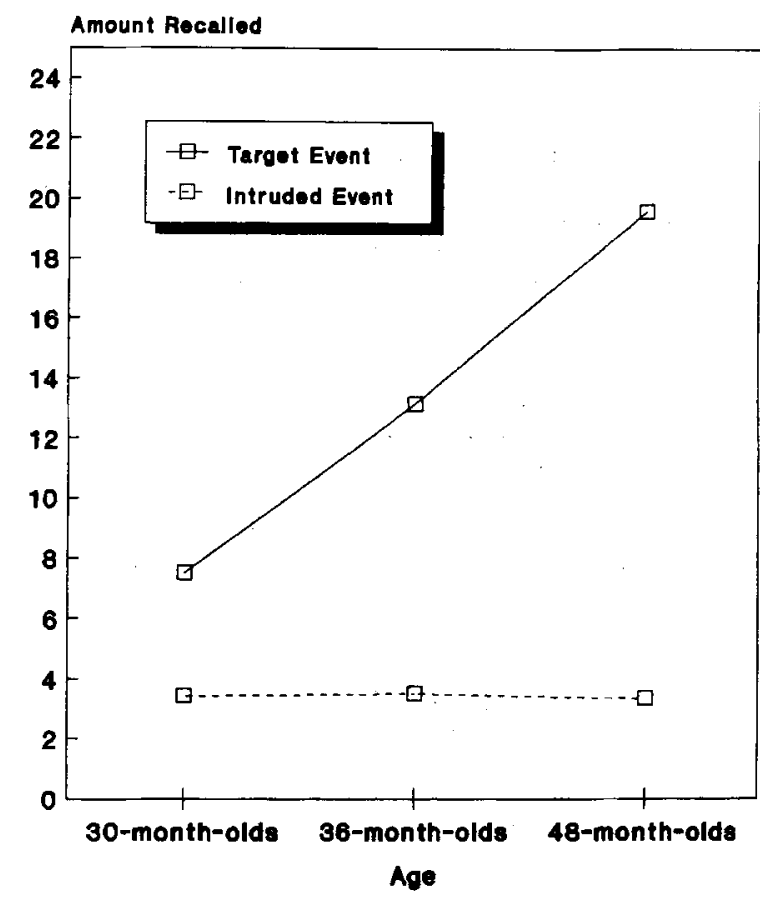

Figure 2. Mean amount of information recalled by preschoolers during their 6th month's interview about the target traumatic event (solid line) and about the intruded event (dashed line).

terview, particularly for the youngest age group. Second, across age, the number of preschoolers reporting an intrusion following a 6-month retention interval decreased with age from $83 \%$ to $50 \%$ to $25 \%$ for the $30-, 36-$, and 48-month-olds, respectively. Interestingly, although it is known that intrusions increase with length of the retention interval (Flin et al., 1992; Poole \& Lindsay, in press; Poole \& White, 1993), this is the first time to our knowledge that a developmental decrease in the number of children who produced intrusions has been reported, especially in the preschool age range.

Next, consider the findings concerning the amount of information intruded after a 6-month retention interval. First, as expected (Howe et al., 1994), there were clear developmental increases in the amount of correct target information recalled. Interestingly, correct target recall exceeded the amount of intruded information recalled at all ages, and children who produced intrusions recalled the same amount of correct target information as did those who did not produce intrusions. Importantly, these findings lead to the conclusion that intruded information may not impede recall of critical target information about traumatic events.

Second, despite the earlier noted age declines in the number of children who produced intrusions, there were no age differences in the amount of information intruded. Thus, although younger children are more likely to intrude information from other, similar traumatic events, the amount of information intruded is age invariant. Again, to our knowledge, results such as these have not been previously reported. What these findings suggest is that although the propensity to intrude declines with age during the preschool years, the amount of intruded information added to recall narratives by younger preschoolers is not greater than that added by older preschoolers. Moreover, although it is clear that preschoolers do include intrusions in their recall narratives, the amount of intruded material does not seem to affect the reporting of correct target information. As well, the amount of correctly recalled material always exceeded that which was intruded. These findings are consistent with the relatively low rates of intrusion previously reported for children's recall of nontraumatic events even in the presence of misinformation (Howe, 1991; Marche \& Howe, in press).
Finally, intrusion rates tended to be independent of stress levels. This is not surprising, since we have previously found that stress is unrelated to levels of correct recall of traumatic events (Howe et al., 1994). Although, clearly, psychometric considerations cannot be ruled out, there is a growing body of evidence attesting to the independence of recall and stress, at least with the moderate levels of stress reported here (Goodman et al., 1991).

These results are somewhat surprising, especially given extant findings that indicate that there are relatively few intrusions in children's recall of well-integrated event information (e.g., Poole \& Lindsay, in press). In fact, these findings suggest that the simple act of reconstructing a traumatic event 6 months later, especially in the younger children, can lead to the reinstatement and consequent intrusion of other whole events. Because all children were clearly able to recall the essence of the target traumatic event, the ability to retain accurate memories of trauma (at least for 6 months) is not in question. However, what these data do caution us about is that memory for trauma is pliable, much like the research on misinformation effects and memory implantation has warned us. Indeed, like this other research, these findings alert us to serious questions about the authenticity of longterm recollections of traumatic events, particularly in the absence of independent verification.

There are at least three explanations for the general trends reported here. First, it is possible that our youngest preschoolers were more likely to intrude information from other events simply because their narrative skills are relatively poor (see chapters in McCabe \& Peterson, 1991). Second, it is possible that age differences exist in source monitoring (e.g., Johnson, Hashtroudi, \& Lindsay, 1993) during the preschool years that would lead younger preschoolers to more frequently confuse or forget the source of different traumatic experiences. Finally, consistent with recent speculation about the role of inhibitory processes in cognitive development (e.g., Harnishfeger \& Bjorklund, 1993), it could be argued that our youngest preschoolers had the poorest ability to inhibit or filter memories of other traumatic events. Regardless of which approach is preferred, additional mechanisms must be fleshed out to account for both the age declines in intrusion frequency and the age invariance of the amount of information intruded.

To conclude, the present findings provide a first look at preschoolers' intrusions in recall of traumatic events. Perhaps the most important finding to emerge from this study is that, regardless of age, the presence of intrusions does not appear to interfere with preschoolers' ability to correctly recall details of a target traumatic event. The implications of our findings are twofold. First, the good news: Although other events frequently intervene between the occurrence of a traumatic event and its subsequent reporting, such experiences do not undermine preschool children's ability to provide accurate and detailed accounts of a target traumatic event. Second, the bad news: Because intrusions often involve similar events and may contain confusions or blends involving central elements of the events, unless independent confirmation is available (as it was in our study), the interviewer has no way of separating target from intruded details about traumatic events. Clearly, independent confirmation of the details of a target event is paramount if we are to differentiate memories for what really happened in the target incident from memories of other, similar events.

\section{REFERENCES}

Brainerd, C. J., \& REYNA, V. F. (in press). Autosuggestibility in memory development. Cognitive Psychology.

CECI, S. J., \& BRUCK, M. (1993). The suggestibility of the child witness: An historical review and synthesis. Psychological Bulletin, 113, 403-439.

Ceci, S. J., Leichtman, M., \& White, T. (in press). Interviewing preschoolers: Remembrance of things planted. In D. Peters (Ed.), The child witness in context: Cognitive, social, and legal perspectives. New York: Kluwer.

Flin, T., Boon, J., Knox, A., \& Bull, R. (1992). The effect of a fivemonth delay on children's and adults' eyewitness memory. British Journal of Psychology, 83, 323-336.

Goodman, G. S., Bottoms, B. L., Schwartz-Kenney, B. M., \& 
RUDY, L. (1991). Children's testimony about a stressful event: Improving children's reports. Journal of Narrative \& Life History, 1 , 69-99.

HARnishfeger, K. K., \& BJorklund, D. F, (1993). The ontogeny of inhibition mechanisms: A renewed approach to cognitive development. In M. L. Howe \& R. Pasnak (Eds.), Emerging themes in cognitive development: Vol. 1. Foundations (pp. 28-49). New York: Springer-Verlag.

HASHER, L., \& GRIFFin, M. (1978). Reconstructive and reproductive processes in memory. Journal of Experimental Psychology: Human Learning \& Memory, 4, 318-330.

HowE, M. L. (1991). Misleading children's story recall: Forgetting and reminiscence of the facts. Developmental Psychology, 27, 746-762.

HowE, M. L. (in press). Interference effects in young children's longterm retention. Developmental Psychology.

Howe, M. L., Courage, M. L., \& Bryant-Brown, L. (1993). Reinstating preschoolers' memories. Developmental Psychology, 29, 854-869.

Howe, M. L., Courage, M. L., \& Peterson, C. (1994). How can I remember when "I" wasn't there: Long-term retention of traumatic experiences and emergence of the cognitive self. Consciousness \& Cognition, 3, 327-355.

Johnson, M. K., Hashtroudi, S., \& LindSay, D. S. (1993). Source monitoring. Psychological Bulletin, 114, 3-28.
Loftus, E. F., \& CoAn, J. (in press). The construction of childhood memories. In D. Peters (Ed.), The child witness in context: Cognitive, social, and legal perspectives. New York: Kluwer.

MARChe, T. A., \& Howe, M. L. (in press). Preschoolers report misinformation despite accurate memory. Developmental Psychology.

MCCABE, A., \& Peterson, C. (Eds.) (1991). Developing narrative structure. Hillsdale, NJ: Erlbaum.

Paris, S. G., \& Lindauer, B. K. (1977). Constructive aspects of children's comprehension and memory. In R. Kail \& J. Hagen (Eds.) Perspectives on the development of memory and cognition (pp. 3560 ). Hillsdale, NJ: Erlbaum.

POOLE, D. A., \& LiNDSAY, D. S. (in press). Interviewing preschoolers: Effects of nonsuggestive techniques, parental coaching, and leading questions on reports of nonexperienced events. Journal of Experimental Child Psychology.

Poole, D. A., \& WhITE, L. T. (1993). Two years later: Effects of question repetition and retention interval on the eyewitness testimony of children and adults. Developmental Psychology, 29, 844-853.

(Manuscript received August 8, 1994; revision accepted for publication September 21, 1994.) 